\title{
Use if! Usenet as a reference tool
}

\section{By Leslie Campbell Rampey}

\section{Useful information can be found amidst the "junk"}

erhaps no electronic resource is so reviled, or so passionately defended, as is Usenet News. A vast conglomeration of electronic bulletin boards, Usenet is home to virtually every interest, pastime, problem, and controversy that delights or troubles the human family. Yet Usenet in itself is a problem to many people. Some computer services administrators deplore it for the inordinate file space and staff time it consumes; many people in general fear it because they believe it to be a sleazy hangout of perverts; some information professionals distrust it because they question the quality of information it houses. On the other hand, those who love Usenet-well, they love Usenet. Some literally cannot go without their daily fix of it; others consider it a second (or even in some extreme cases a primary) home where they find longed-for acceptance and understanding.

Where on this spectrum do or should reference librarians find themselves? Although his or her personal feelings about Usenet are each reference librarian's private business, the fact is that Usenet is a potentially rich (albeit not faultless) source of information. It should be a tool in the reference librarian's kit - one that he or she cannot afford to ignore and should be practiced at using. It also is reasonable to assert that the smaller the library the greater Usenet's reference potential.

\section{How Usenet is organized}

To test the validity of those last two statements, we should examine the structure of Usenet.
Although electronic information has been characterized fairly as chaotic, Usenet does have a coherent structure of sorts. It's not the LC Classification System, but it's hardly mysterious.

Usenet is divided into hierarchies. ${ }^{1}$ Sometimes it is said that several groups are the "common" or "traditional" ones. The fact is, however, that some that might once have been labeled "other" have outdistanced the former. For finding information, the most valuable of the hierarchies probably are "rec," "sci," "soc," "comp," "bionet," "biz," "k12," and the everproblematical "alt." If we exclude "alt" for a moment, it shouldn't be difficult for a reference librarian to decide into which hierarchy a given subject probably falls.

The only caveat is to remember that "rec" encompasses a good deal more than most of us might attribute to the word "recreation." Indeed, the "rec" hierarchy includes those general subject areas that we might more likely refer to as "the arts and humanities"-fine arts, literature, and drama.

\section{A few words about the "alt" hierarchy}

The second thing we need to remember is simply, "Remember 'alt'; don't ever forget 'alt." As I write, the "alt" hierarchy on my newsreader includes 437 subheadings, and it no doubt will have more by the time this article sees print. There's no way to know what is in "alt" other than to keep current with it. That's also true of the other Usenet hierarchies, but not to the degree it is true with "alt." At least in "sci," for example, one has a pretty dependable idea of what can be found there. New subheadings and new groups will be added, of course, but one knows that they all will be about science. 
That cannot be said of "alt." It's a world of information unto itself, sometimes paralleling (but not duplicating) topics found in the other hierarchies. It's very true, as some Usenet detractors claim, that much of what is in "alt" is pure junk-for example, the infamous group "alt barney.dinosaur die die die." (Before people are too quick to indict all of Usenet for this failing, however, they should take a walk around any library periodicals section where they would find that about the same is true to about the same degree.) The fact that junk exists should not obscure the very real information that can be found. Examples are endless, so here's just one I found on a recent trek through "alt": How else could a small library provide immediate access to an episode-byepisode guide to the TV series $M^{*} A^{*} S^{*} H$ but in "alt.tv.mash"? That, by the way, is not available in the more standard "rec.arts.tv. ..." One simply would need to know about the "alt.tv . . subheading. That is true over and over again, all up and down the "alt" hierarchy.

\section{Usenet in the reference environment}

Assuming that you're familiar with the Usenet landscape, how would you use it as a reference tool? Approach it first the same way you would a potential interlibrary loan transactionthat is, first make sure that the item or suitable substitute does not exist locally. If it's a specific item (book, article, etc.), you would choose the standard interlibrary loan route. If, however, the request involves a piece of information or documentation for which the location is unknown, Usenet might be the way to go.

Select the group or groups you think might be a likely source of the information. You could get very lucky and find that the specific piece of information you are hunting is a standard part of the newsgroup always up for view. That is the case in the aforementioned example of the $M^{*} A^{*} S^{*} H$ episode guide. It exists as an FAQ (frequently asked question) that permanently resides at the top of the group. Be on the lookout for these FAQs. If they don't contain the information themselves, they might tell you where it can be located easily-perhaps a gopher, FTP, or Web site.

If no FAQs exist or the information you seek is not in them, you still might get lucky if the subject is a hot topic currently under discussion in the group. What would be left for you and your client to do in that case is to evaluate the reliability of the posts you find.

\section{Posting queries to Usenet}

If you believe that you have found the most likely group(s), but the information you need is not in evidence, you might want to post a query. This is where using Usenet can be both tricky and very rewarding.

If you are fortunate enough that your institution has its own Usenet newsfeed, you should know (or can easily learn locally) how to go about posting a query. If that is not the case, and you have been depending on a public gopher site to read Usenet, you already are aware that your access is less than dependable. Posting is going to be even more difficult. I have had some success e-mail posting to the public sites listed by Yanoff, ${ }^{2}$ but that process is not hassle-free. For one thing, it is difficult to be certain which site carries which groups. If you do go the public reading/posting route, be sure to request in your post that all replies be e-mailed to you personally or to your client as it might not be easy for you to access the group on a regular basis.

Another option-the one I advise- - is for reference librarians to maintain some sort of personal Usenet access, at least until such time as their institutions may provide a local newsfeed. Many commercial Internet providers now feature Usenet access, but the expense of using a personal commercial account in a work environment might be prohibitive. A more practical option is for the reference librarian to have an account on one of the several FreeNets that provide Usenet access. ${ }^{3}$ That is the solution I have found, and it has been working for me. At least I know that I have a dependable and hassle-free reading/posting capability.

\section{Real life examples of Usenet reference queries}

In recent months, I have been using Usenet as a reference tool more and more. I've had some particularly good luck with the "rec" hierarchy. For example, I found several people who helped identify postage stamps (and in the process received a very generous offer to donate a set of Scott catalogs to our library); I received some helpful ideas on how a left- handed person might be taught to knit; and I obtained information about ordering tickets for NASCAR events at the Talladega Speedway. In the "k12" hierarchy, I turned up a correspondent willing to snail-mail one of our patrons an official copy of the proposed national standards in geography education. As far as I know, none of this 


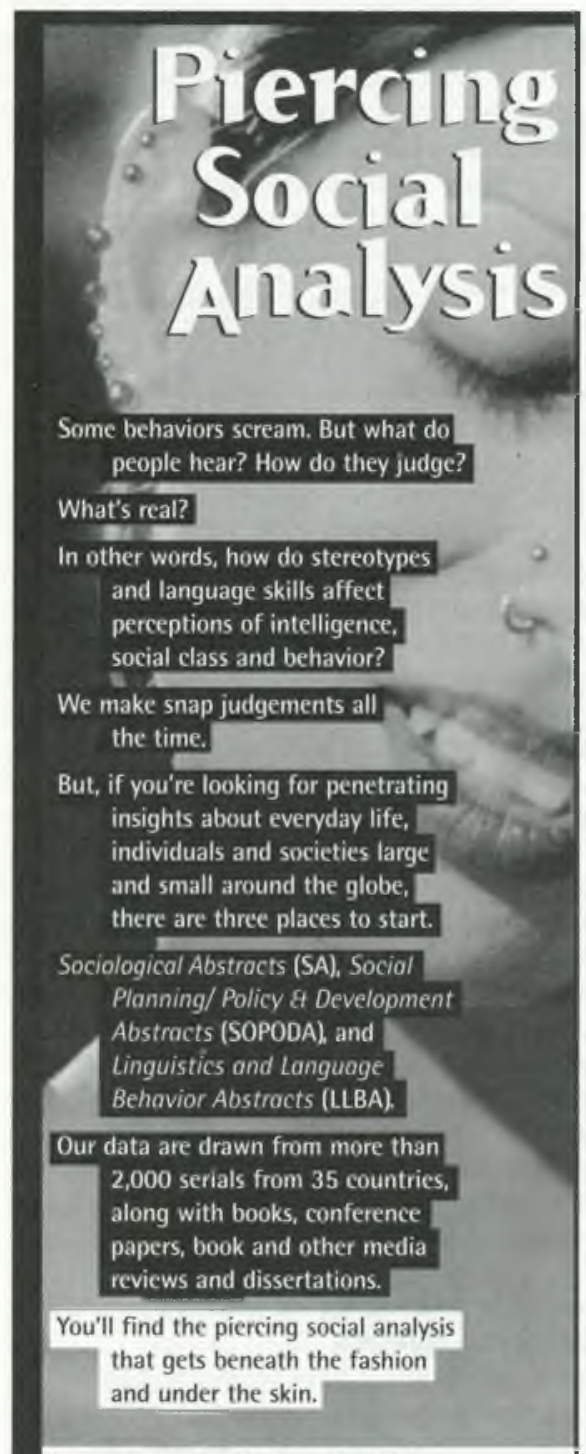

\section{sociological} abstracis

PO. Box 22206 Son Diego, CA 92192.0206 619/695-8803 Fax: 695-0416

Internet socio@ cerfnet.com User Assistance B00/752-3945

The SAI fomily of services: Sociological Abstrocts (SA) Social Planning/Policy \& Development Abutracts (SOPODA). linguistics and language Behavior Abstracts $(\mathrm{MB} A) \cdot$ wociokile

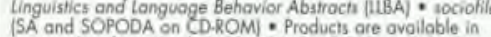
print; online from Knighi-Ridder, DUMDI, OCIC, ond Ovid; on CD.ROM from SilverPlatter, EBSCO and Ovid; on mognetic tape via SAI direct. Document delivery ovailoble vig ma SOCIOLOGY'Exprou: 800/313.9960 415/259.5013 Fax 415/250-5058; emoil: socobleebscodoc com information was available in our library, nor was I able to pin down specific items to request through interlibrary loan.

\section{Reference benefits of Usenet}

While it is true that there are also e-mail discussion lists where one might obtain similar information, it can be difficult to know which list might be best to query unless you are a subscriber. And you simply cannot subscribe to all e-mail lists just on the off-chance that one day one of them might be a potential reference resource. But you can periodically browse Usenet to be at least vaguely familiar with its reference possibilities.

Two aspects of using Usenet as a reference tool should be kept in mind. First, most Usenet groups simply would not exist at all unless there were people out there interested in reading and posting to them. And what better people to ask about a particular subject than those you know have an interest, sometimes a passionate one, in that subject? They might not all be highly qualified experts, but often they at least can offer useful advice and put you on the track of further information. Second, it's been my experience that library users are thrilled and very impressed to receive information this waythat is, from an unknown real live person who is willing to take the time to help them. A happy user is good for the library and not incidentally for the reference librarian.

Although the less than sterling reputation Usenet suffers in some quarters might discourage reference librarians from taking advantage of it, the truth is that it can be very fruitfully exploited as a reference tool. Moreover, it can infinitely expand the walls of small libraries in very exciting ways. So, use it!

\section{Notes}

1. A number of good basic descriptions of Usenet exist. I suggest either: Mark Veljkov and George Hartnell, "Using and Navigating Usenet," vol. 3 of Pocket Guides to the Internet (Westport, Conn.: Mecklermedia, 1994); Gord Nickerson, "Usenet," Computers in Libraries 12 (April 1992): 31-34.

2. See Scott Yanoff's regularly updated "Special Internet Connections" at http://Www. uwm.edu/Mirror/inet.services.html.

3. To learn how to locate and join FreeNets, see my "Confessions of a Free-Net Junkie," Internet Homesteader 1 (September 1994): 1, $5-7$. 